\title{
Estimation of solar radiation from cloud cover data of Bangladesh
}

\author{
Md. Nazmul Islam Sarkar ${ }^{*}$ (B)
}

\begin{abstract}
In this study, an analysis of the monthly mean values of the fraction of the sky covered by clouds ( $C$ ) of all types and the duration of bright sunshine hours $(S)$ and global solar radiation on the horizontal surface $(H)$ was carried out to establish relationship for solar radiation estimation for Bangladesh. The relationship between $C$ and $\left(1-S / S_{0}\right)$, where $S_{0}$ is the maximum possible hours of sunshine, was found to be nonlinear. The relationship between $C$ and $\left(1-H / H_{0}\right)$, where $H_{0}$ is the extraterrestrial solar radiation, was also found to be nonlinear. Few quadratic regression equations were derived for different regions of Bangladesh. The data were separated in Zone 1 (below the tropic of cancer, i.e., $\leq 23.5^{\circ} \mathrm{N}$ ) and Zone 2 (above the tropic of cancer, i.e., $\geq 23.5^{\circ} \mathrm{N}$ ). All the developed models were checked statistically. It was found that it is always better to estimate solar radiation from sunshine duration as it gives the best estimation and accuracy, but if there is no sunshine duration data available for a site, then solar radiation can be estimated directly from cloud cover data. Estimating sunshine duration first from cloud data to estimate solar radiation introduces more error as it has to go through the modeling stage twice. In case of the need of sunshine duration data only, the estimation from cloud cover is quite helpful. It was also found from the study that for small country like Bangladesh separating data according to latitude has insignificant effect.
\end{abstract}

Keywords: Sunshine duration, Cloud cover, Global solar radiation estimation, Correlation models

\section{Background}

Bangladesh is a small south Asian country with an area of $147,570 \mathrm{~km}^{2}$ and located between latitudes $20.59^{\circ}-$ $26.63^{\circ} \mathrm{N}$ and longitudes $88.01^{\circ}-92.67^{\circ} \mathrm{E}$. Among fossil fuel, Bangladesh has only natural gas that is used in power generation in the country (Ahiduzzaman and Islam 2011). According to Bangladesh Power Development Board (BPDB), Bangladesh has a total installed capacity of $11,532 \mathrm{MW}$, and among them $62.76 \%$ of the total generation comes from natural gas (Bangladesh Power Development Board 2015). A large amount of imported furnace oil is burnt to produce $20.45 \%$ of total power which emits a huge amount of $\mathrm{CO}_{2}$ and other toxic gases. The estimated reserve of natural gas which is around 13.75 Tcf would meet the country's demand till 2015. After that, there will be a shortage of gas supply which would rise to 4421 MMcfd by 2025 . Therefore, an additional $8.35 \mathrm{Tcf}$ supply of gas is to be met by some

*Correspondence: sarkarmni@gmail.com

Institute of Energy, University of Dhaka, Dhaka 1000, Bangladesh other means (Ahiduzzaman and Islam 2011). Fortunately, Bangladesh receives moderate amount of daily sunshine of $4.5-4.8 \mathrm{kWh} / \mathrm{m}^{2}$ which can be proved very significant for a sustainable power sector (Mondal and Islam 2011).

Knowledge of the amount of global solar radiation of an area is essential to design various solar energy systems. Unfortunately, solar radiation measurement instruments are costly and require proper maintenance and calibration. Therefore, solar radiation data are not readily available to the designers of solar energy systems, decision makers, or the investors. Being a developing country, Bangladesh has very less investment in technology to measure solar radiation all over the country. In fact, there is no solar radiation measurement instrument installed in any station of Bangladesh Meteorological Department (BMD 2015). So there is a need to develop methods for estimating solar radiation from other meteorological parameters like sunshine hour data or cloud cover data.

In past, many empirical models were developed by many researchers using various meteorological parameters like sunshine hours (Angstrom 1924), precipitation
定

(c) 2016 Sarkar. This article is distributed under the terms of the Creative Commons Attribution 4.0 International License (http:// creativecommons.org/licenses/by/4.0/, which permits unrestricted use, distribution, and reproduction in any medium, provided you give appropriate credit to the original author(s) and the source, provide a link to the Creative Commons license, and indicate if changes were made. 
(Hargreaves and Samani 1982), air temperature (Jong and Stewart 1993), relative humidity (Elagib et al. 1998), and cloudiness (Black 1956) to establish a relationship with solar radiation. Bakirci (2015) has developed some new empirical models for predicting the monthly mean diffuse solar radiation on a horizontal surface for typical cities in Turkey. Chelbi et al. (2015) have done the solar radiation mapping using sunshine duration-based models and interpolation techniques for Tunisia. Simple correlation for estimating the global solar radiation on horizontal surfaces for India was done by Katiyar and Pandey (2010). Liu et al. (2015) found the changes in the relationship between solar radiation and sunshine duration in large cities of China. Robaa (2008) has done the evaluation of sunshine duration from cloud data in Egypt. Yang et al. (2012) have done the hourly solar irradiance timeseries forecasting using cloud cover index. Nimnuan and Janjai (2012) have found another approach for estimating average daily global solar radiation from cloud cover in Thailand. New types of simple nonlinear models to compute solar global irradiance from cloud cover amount were found by Badescu and Dumitrescu (2014). Ehnberg and Bollen (2005) have done a simulation of global solar radiation based on cloud observations. Reddy (1974) has developed an empirical method for estimating sunshine from total cloud amount. Morf (2014) has done sunshine and cloud cover predictions based on Markov processes. Babatunde and Aro (1995) have established a relationship between "clearness index" and "cloudiness index" at a tropical station, for instance, Ilorin, Nigeria. Al-Mostafa et al. (2014) have done a review of sunshine-based global radiation models. Manzano et al. (2015) established a method to estimate the daily global solar radiation from monthly data.

However, most of the models used sunshine duration to estimate solar radiation (Al-Mostafa et al. 2014). The most widely used and accepted method is that of Angstrom (1924) who proposed a linear relationship between the ratio of average daily global radiation to the corresponding value on a clear day and the ratio of average daily sunshine duration to the maximum possible sunshine duration.

Although there are 35 sunshine duration measurement stations of BMD installed in different areas of Bangladesh, there are still too few of them to cover the whole country. Therefore, it is essential to estimate solar radiation from other climatological parameters like cloud cover. In fact, cloud cover data are more numerous and in some instances geographically better distributed than sunshine hour data (Iqbal 1983).

Furthermore, there is no publication or previous study on the prediction of solar radiation from cloud cover data of Bangladesh. Therefore, the main objective of this study is to establish simple models to estimate solar radiation from cloud cover precisely. This is done by two different ways: First, quadratic models were developed for different regions of Bangladesh to estimate sunshine duration from cloud cover data, and then using models already established by other researchers (Al-Mostafa et al. 2014; Chelbi et al. 2015; Li et al. 2011; Ampratwum and Dorvlo 1990; Sen 2007) solar radiation was estimated. Second, regression models are developed to estimate solar radiation directly from cloud cover data. Later on, the results of these two different ways are compared by statistical error tests.

\section{The climate of Bangladesh}

Bangladesh is a small south Asian country which has an area of $147,570 \mathrm{~km}^{2}$ and located between latitudes $20.59^{\circ}-26.63^{\circ} \mathrm{N}$ and longitudes $88.01^{\circ}-92.67^{\circ} \mathrm{E}$. It is a low-lying plain situated on deltas of large rivers flowing from the Himalayas. The climate of Bangladesh is a subtropical climate with high seasonal variations in rainfall, moderately warm temperatures, and high humidity (Rashid 2006). There are four distinct seasons: (1) the dray winter season from December to February, (2) the pre-monsoon hot summer season from March to May, (3) the rainy monsoon season from June to September, and (4) the post-monsoon autumn season which lasts from October to November (Shahid 2010). Because of these distinct seasons, Bangladesh receives variable rainfall according to place and time. Rainfall varies from 1400 to $4400 \mathrm{~mm}$ from west to east, respectively. The rainfall gradient is $7 \mathrm{~mm} / \mathrm{km}$ from west to east of the country (Shahid 2010). More than $75 \%$ of the total rainfall occurs during the monsoon. Therefore, in terms of cloud coverage, we can expect clear days (0-2 oktas) in the dry winter season (from December to February), mixed days (2-4 oktas) in both pre- and post-monsoon seasons (from March to May and from October to November, respectively), and overcast days (4-8 oktas) in the rainy monsoon season (from June to September) (Khadem et al. 2007). During winter, the average temperature of the country ranges from 7.2 to $12.8{ }^{\circ} \mathrm{C}$ and during summer 23.9-31.1 ${ }^{\circ} \mathrm{C}$ (Shahid 2010). The coldest month is January and the hottest month is May in Bangladesh. In winter, there are also foggy and misty days from December to January which might also restrict solar insolation to reach the surface.

\section{Methods}

\section{Estimation of sunshine duration from cloud amount}

From ancient time, people knew the relationship between sunshine and cloud cover. Early researchers also knew that there is an inverse relationship between insolation and the amount of sky covered by clouds (Kimball 1919). 
The inverse relationship results from the fact that sunshine duration $(S)$ records are usually caused by the sun being obstructed by cloud cover $(C)$ of sufficient opacity (Rangarajan et al. 1984). The relationship between mean cloudiness $C$ and the global solar radiation $\mathrm{H}$ is given by the well-known Angstrom-Savinov formula (Rangarajan et al. 1984) as:

$$
H=H_{0}[1-(1-k) C]
$$

where $H_{0}$ is the estimated daily global radiation for a cloudless sky, $C$ is the monthly average fraction of the daytime sky obscured by clouds, and $k$ is a constant defining the transmission of solar radiation within the clouds. Generally, the value of $k$ varies between 0.55 in high latitudes and 0.33 in low latitudes (Mani et al. 1967). This formula is very similar to the Anstrom-Prescott (A-P) formula relating sunshine duration $(S)$ with global solar radiation $(H)$ as:

$$
H=H_{0}\left[a+b\left(\frac{S}{S_{0}}\right)\right]
$$

where $N$ is the maximum possible duration of bright sunshine during the day and $a$ and $b$ are regression coefficients to be found. According to Rangarajan et al. (1984), if the estimate is correct and free from visual errors, then the total cloud amount should follow the relationship as:

$$
C=\left(1-S / S_{0}\right)
$$

If Eq. (3) is valid, then all points should lie clustered along the straight line passing through the origin and the $(1,1)$ point. Unfortunately, cloud cover estimation is not free from error. Rather it depends on the perspective of the viewer. In some extreme cases, it is possible that a small hole in the cloud could remain open for a long period of time or one small cloud could keep the sun obscured for a long time while moving with the sun (Iqbal 1983). The reflection of solar radiation from the edges could also increase the insolation enough to burn the card of Campbell-Stokes sunshine recorder. So the plot of Eq. (3) will not coincide with $y=x$ line. Rather it will deviate from ideal conditions. Therefore, a correlation is necessarily to be found to estimate sunshine duration. In this study, we have established correlations between cloud cover with sunshine hour for different stations of Bangladesh.

Using the correlations found from (3), we can estimate $S / S_{0}$. Then, multiplying this value with $S_{0}$ will provide us the value of $S$.

\section{Estimation of solar radiation from estimated sunshine duration}

We can use the estimated sunshine duration data as described in the previous section to further estimate the solar radiation of the region. Different regression models to estimate global solar radiation on the horizontal surface from sunshine duration which are proposed in the literature are given in Table 1 (Almorox and Hontoria 2004; Angstrom 1924; Prescott 1940; Akinoglu and Ecevit 1990; Ertekin and Yaldiz 2000; Ampratwum and Dorvlo 1990; Sen 2007). The models that can be used to estimate solar radiation from sunshine duration for Bangladesh are given in Table 2. We have used the general Angstrom-Prescott type model to estimate solar radiation from sunshine duration estimated previously from cloud cover data.

In the models in Table $1, H$ is the global solar radiation on horizontal surface $\left(\mathrm{kWh} / \mathrm{m}^{2}\right), H_{0}$ is the extraterrestrial radiation $\left(\mathrm{kWh} / \mathrm{m}^{2}\right), S$ is the sunshine duration (h), $S_{0}$ is the day length (h), and $a, b, c$, and $d$ are the empirical coefficients.

Extraterrestrial solar radiation $H_{0}$ can be calculated according to Duffie and Beckman (2006):

$$
\begin{aligned}
H_{0}= & \frac{\left(24 \times 3600 G_{\mathrm{sc}}\right)}{\pi}\left(1+0.033 \cos \frac{360 D}{365}\right) \\
& \times\left(\cos \phi \cos \delta \sin \omega_{\mathrm{s}}\right)+\frac{\left(\pi \omega_{\mathrm{s}}\right)}{180} \sin \phi \sin \delta
\end{aligned}
$$

where $G_{\mathrm{sc}}$ is the solar constant $\left(1367 \mathrm{~W} / \mathrm{m}^{2}\right), D$ is the day number of the year counting from first January, $\phi$ is the latitude of the place $\left(^{\circ}\right), \omega_{\mathrm{s}}$ is the sunset hour angle $\left({ }^{\circ}\right)$, and $\delta$ is the solar declination $\left(^{\circ}\right)$.

Table 1 Empirical models to calculate solar radiation from sunshine duration

\begin{tabular}{lll}
\hline Models & Regression equations & Source \\
\hline Linear & $H / H_{0}=a+b\left(S / S_{0}\right)$ & Angstrom-Prescott (1924, 1940) \\
Quadratic & $H / H_{0}=a+b\left(S / S_{0}\right)+c\left(S / S_{0}\right)^{2}$ & Akinoglu and Ecevit (1990) \\
Third degree & $H / H_{0}=a+b\left(S / S_{0}\right)+c\left(S / S_{0}\right)^{2}+d\left(S / S_{0}\right)^{3}$ & Ertekin and Yaldiz (2000) \\
Logarithmic & $H / H_{0}=a+b \cdot \log \left(S / S_{0}\right)$ & Ampratwum and Dorvlo (1990) \\
Exponential & $H / H_{0}=a \cdot \exp \left[b \cdot\left(S / S_{0}\right)\right]$ & Almorox and Hontoria (2004) \\
Power & $H / H_{0}=a \cdot\left(S / S_{0}\right)^{b}$ & Sen (2007) \\
\hline
\end{tabular}


Table 2 Regression equations to estimate solar radiation from sunshine duration for Bangladesh

\begin{tabular}{llll}
\hline$\#$ & Annual models & Equations & $\boldsymbol{R}^{\mathbf{2}}$ \\
\hline 1 & Linear & $H / H_{0}=0.4256\left(S / S_{0}\right)+0.2199$ & 0.8888 \\
2 & Quad. & $H / H_{0}=0.749\left(S / S_{0}\right)^{2}-0.3752\left(S / S_{0}\right)+0.417$ & 0.8920 \\
3 & Cubic & $H / H_{0}=3.1987\left(S / S_{0}\right)^{3}-4.4223\left(S / S_{0}\right)^{2}+2.3158\left(S / S_{0}\right)-0.0306$ & 0.8899 \\
4 & Expo. & $H / H_{0}=0.2673 \exp \left[0.9422\left(S / S_{0}\right)\right]$ & 0.8913 \\
5 & Log. & $H / H_{0}=0.2152 \ln \left(S_{S} / S_{0}\right)+0.5916$ & 0.8729 \\
6 & Power & $H / H_{0}=0.6093\left(S / S_{0}\right)^{0.478}$ & 0.8804 \\
\hline
\end{tabular}

The value of $\delta$ and $\omega_{\mathrm{s}}$ can be calculated from Eqs. (5) and (6), respectively (Duffie and Beckman 2006):

$$
\begin{aligned}
& \delta=23.45 \sin \left[\frac{360(D+284)}{365}\right] \\
& \omega_{\mathrm{s}}=\arccos [-\tan (\delta) \tan (\phi)]
\end{aligned}
$$

The day length $S_{0}$ can be calculated using the value of $\omega_{\mathrm{s}}$ as follows (Duffie and Beckman 2006):

$$
S_{0}=\frac{2}{15} \omega_{\mathrm{s}}
$$

Now, the ratio $H / H_{0}$ can be found by substituting the values of measured global solar radiation $(H)$ and extraterrestrial radiation $H_{0}$. This ratio $H / H_{0}$ is known as clearness index which gives the percentage deflection by the sky of the incoming global radiation and changes in the atmospheric conditions in a given locality (Iqbal 1983).

Estimation of solar radiation directly from cloud cover data In 1956, Black used data of 88 stations from all over the world to develop an empirical relationship between solar radiation and cloud cover (Black 1956). He used the mean monthly values for 88 stations and performed a regression analysis to find the following relationship between $H / H_{0}$ and $C$ :

$$
\frac{H}{H_{0}}=0.803-0.340 C-0.458 C^{2}
$$

Unfortunately, this relationship can produce substantial amount of error as according to Black himself (Black 1956): (1) Mean monthly values were calculated from the maximum numbers of years and (2) different instruments have been used in different stations and no attempts have been made to reduce these instruments to a common standard.

Therefore, we have done a regression analysis to establish some new models to estimate solar radiation $(H)$ directly from cloud fraction $(C)$ for Bangladesh. To do this, we have established a relationship between clearness index, $H / H_{0}$, and cloud fraction, $C$. The value of $H / H_{0}$ can be determined similarly as shown in section "Estimation of solar radiation from estimated sunshine duration."

\section{Data}

In this work, the measured daily global solar radiation data are taken from Institute of Energy (previously known as Renewable Energy Research Center), University of Dhaka and Bangladesh Meteorological Department (BMD). Measured time-series data of global solar radiation were available for five sites, and sunshine duration and cloud cover data were available for 34 stations of BMD.

Institute of Energy (RERC) measured global solar radiation from January 2003 to December 2005 using two Eppley PSP Pyranometers at 1-min interval for $24 \mathrm{~h}$. In $\mathrm{BMD}$, sunshine duration data were recorded using Campbell-Stokes sunshine recorders. Cloud cover data were also taken from ground observations at 1 -h interval by estimating the total fraction of the celestial dome covered by clouds of any thickness and then rounded to the nearest one-eighth, or okta. The data are divided into two zones for better estimation. The data of Zone 1 come from stations having latitude less than those of Tropic of Cancer $\left(23.5^{\circ} \mathrm{N}\right)$, and the second zone is formed with stations having latitude greater than Tropic of Cancer $\left(23.5^{\circ} \mathrm{N}\right)$. This is done to check the effect of latitude on the regression equations as well as to find a more accurate estimation. Table 3 shows detailed information about the stations and their period of observation of meteorological data, and Fig. 1 shows the geographical distribution of BMD stations over Bangladesh.

German Aerospace Center (DLR) time-series data (German Aerospace Center 2015) of global solar radiation was also available for ten sites from Solar and Wind Energy Resource Assessment (SWERA) project database (Schillings et al. 2014). The DLR data were not used to find model parameters; rather it was used to have an assumption of the validity of the models. 
Table 3 Geographical locations and period of data of the BMD stations

\begin{tabular}{|c|c|c|c|c|c|c|c|}
\hline \multirow[t]{2}{*}{ Station name } & \multirow[t]{2}{*}{ WMO station no. } & \multirow[t]{2}{*}{ LAT. $\left({ }^{\circ} \mathrm{N}\right)$} & \multirow[t]{2}{*}{ LONG. ( $\left.{ }^{\circ} \mathrm{E}\right)$} & \multirow[t]{2}{*}{ Elev. $(\mathrm{m})$} & \multicolumn{3}{|l|}{ Period of observations } \\
\hline & & & & & Global solar radiation & Sunshine duration & Cloud cover \\
\hline \multicolumn{8}{|l|}{ Zone 1} \\
\hline Teknaf & 41998 & 20.87 & 92.26 & 4 & - & 1977-2013 & $1977-2013$ \\
\hline Cox's Bazar & 41992 & 21.46 & 91.98 & 4 & - & $1961-2013$ & $1948-2013$ \\
\hline Kutubdia & 41989 & 21.83 & 91.84 & 6 & - & 1984-2013 & $1985-2013$ \\
\hline Khepupara & 41984 & 21.98 & 90.22 & 3 & - & 1988-2013 & 1974-2013 \\
\hline Hatiya & 41963 & 22.29 & 91.13 & 4 & - & 1985-2013 & $1966-2013$ \\
\hline Chittagong & 41978 & 22.34 & 91.79 & 6 & - & $1961-2013$ & 1949-2013 \\
\hline Patuakhali & 41960 & 22.36 & 90.34 & 3 & - & 1985-2013 & 1973-2013 \\
\hline Mongla & 41958 & 22.43 & 89.66 & 4 & - & $2001-2013$ & $1991-2013$ \\
\hline Sandwip & 41964 & 22.5 & 91.46 & 6 & - & $1987-2013$ & 1967-2013 \\
\hline Sitakunda & 41965 & 22.64 & 91.64 & 4 & - & 1977-2013 & 1977-2013 \\
\hline Rangamati & 41966 & 22.67 & 92.2 & 63 & 2005 & 1987-2013 & $1957-2013$ \\
\hline Satkhira & 41946 & 22.68 & 89.07 & 6 & 2005 & 1984-2013 & 1948-2013 \\
\hline Barisal & 41950 & 22.7 & 90.36 & 4 & - & 1967-2013 & 1949-2013 \\
\hline Bhola & 41951 & 22.7 & 90.66 & 5 & - & $1981-2013$ & 1966-2013 \\
\hline Khulna & 41947 & 22.8 & 89.58 & 4 & - & 1984-2013 & 1948-2013 \\
\hline Maijdee Court & 41953 & 22.83 & 91.08 & 6 & - & 1985-2013 & $1951-2013$ \\
\hline Feni & 41943 & 23.01 & 91.37 & 8 & - & 1985-2013 & 1973-2013 \\
\hline Madaripur & 41939 & 23.17 & 90.18 & 5 & - & 1988-2013 & 1977-2013 \\
\hline Jessore & 41936 & 23.17 & 89.22 & 7 & - & 1967-2013 & 1948-2013 \\
\hline Chandpur & 41941 & 23.26 & 90.67 & 7 & - & 1977-2013 & 1964-2013 \\
\hline Comilla & 41933 & 23.48 & 91.19 & 10 & - & $1981-2013$ & 1948-2013 \\
\hline \multicolumn{8}{|l|}{ Zone 2} \\
\hline Faridpur & 41929 & 23.61 & 89.84 & 9 & - & 1985-2013 & 1948-2013 \\
\hline Chuadanga & 41926 & 23.65 & 88.82 & 0 & 2005 & 2003-2013 & $2001-2013$ \\
\hline Dhaka & 41923 & 23.78 & 90.39 & 9 & $2003-2005$ & $1961-2013$ & 1953-2013 \\
\hline Ishurdi & 41907 & 24.12 & 89.04 & 14 & - & 1985-2013 & $1961-2013$ \\
\hline Tangail & 41909 & 24.15 & 89.55 & 10 & - & 1987-2013 & 1987-2013 \\
\hline Srimangal & 41915 & 24.29 & 91.73 & 23 & - & 1986-2013 & 1948-2013 \\
\hline Rajshahi & 41895 & 24.35 & 88.56 & 20 & - & 1979-2013 & 1964-2013 \\
\hline Mymensingh & 41886 & 24.75 & 90.41 & 19 & - & 1979-2013 & 1948-2013 \\
\hline Sylhet & 41891 & 24.88 & 91.93 & 35 & - & 1962-2013 & 1956-2013 \\
\hline Bogra & 41883 & 24.88 & 89.36 & 20 & 2005 & $1961-2013$ & 1948-2013 \\
\hline Dinajpur & 41863 & 25.63 & 88.66 & 37 & - & 1989-2013 & 1948-2013 \\
\hline Rangpur & 41859 & 25.72 & 89.26 & 34 & - & 1979-2013 & 1954-2013 \\
\hline Syedpur & 41858 & 25.75 & 88.92 & 0 & - & $2003-2013$ & $1991-2013$ \\
\hline
\end{tabular}

\section{Statistical evaluation}

To evaluate different models developed in this study, six statistical quantitative indicators were used. These quantitative indicators are: the coefficient of determination $\left(R^{2}\right)$, mean percentage error (MPE), mean bias error $(\mathrm{MBE})$, root mean square error (RMSE), mean absolute relative error (MARE), and $t$-statistic ( $t$-stat). These indicators can be calculated as follows (Despotovic et al. 2015).

In case of sunshine duration estimation,

$$
\begin{aligned}
& R^{2}=1-\frac{\sum_{i=1}^{n}\left(S_{i, \mathrm{~m}}-S_{i, \mathrm{c}}\right)^{2}}{\sum_{i=1}^{n}\left(S_{i, \mathrm{~m}}-S_{\mathrm{m}, \mathrm{avg}}\right)^{2}} \\
& \mathrm{MPE}=\frac{1}{n} \sum_{i=1}^{n}\left(\frac{S_{i, \mathrm{c}}-S_{i, \mathrm{~m}}}{S_{i, \mathrm{~m}}} \times 100\right)
\end{aligned}
$$

$\mathrm{MBE}=\frac{1}{n} \sum_{i=1}^{n}\left(S_{i, \mathrm{~m}}-S_{i, \mathrm{c}}\right)$ 


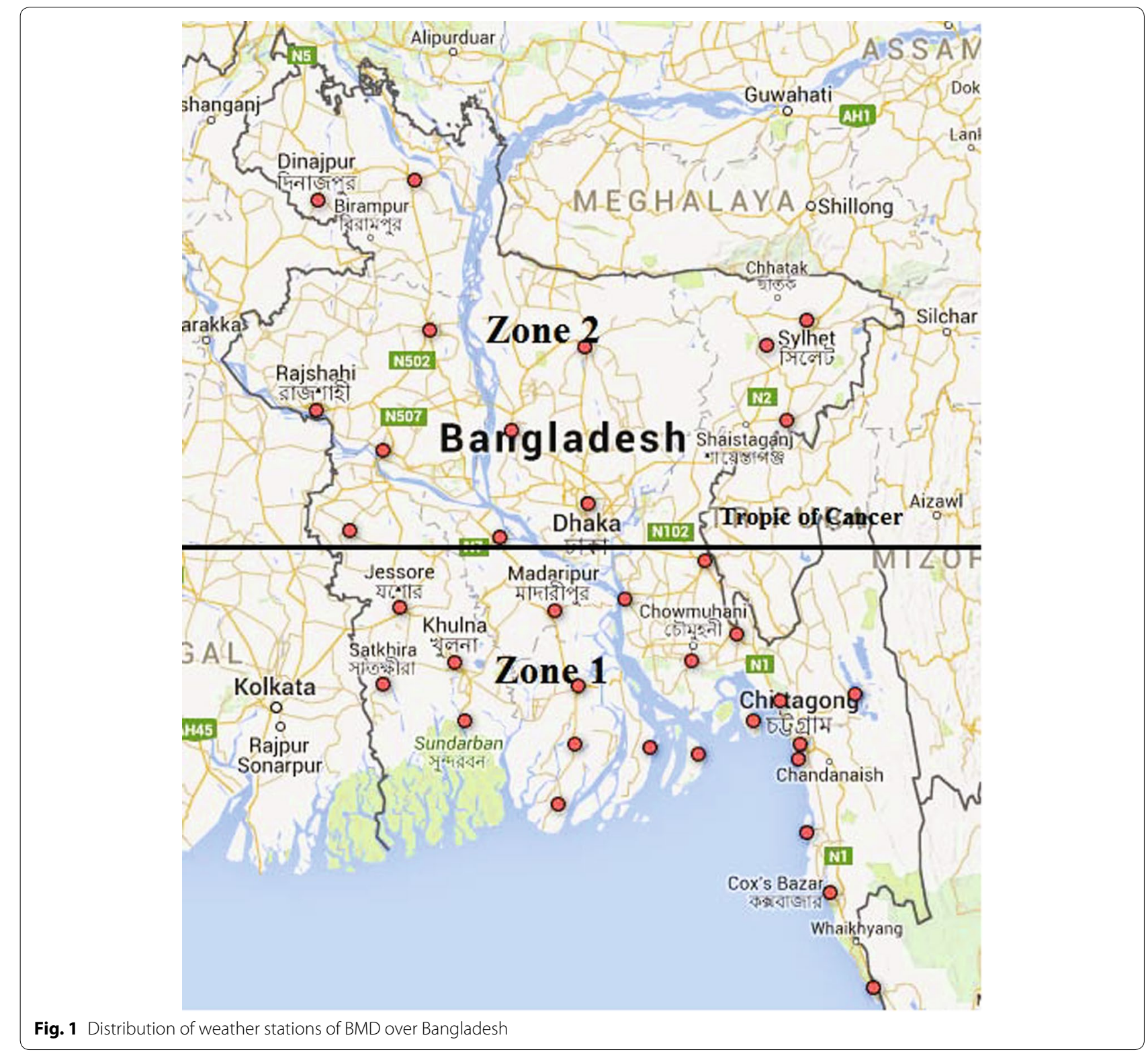

$$
\begin{aligned}
& \text { RMSE }=\sqrt{\frac{1}{n} \sum_{i=1}^{n}\left(S_{i, \mathrm{~m}}-S_{i, \mathrm{c}}\right)^{2}} \\
& \text { MARE }=\frac{1}{n} \sum_{i=1}^{n}\left|\frac{S_{i, \mathrm{~m}}-S_{i, \mathrm{c}}}{S_{i, \mathrm{~m}}}\right| \\
& t \text {-stat }=\sqrt{\frac{(n-1) \mathrm{MBE}^{2}}{\mathrm{RMSE}^{2}-\mathrm{MBE}^{2}}}
\end{aligned}
$$

where $S_{i, \mathrm{~m}}$ and $S_{i, \mathrm{c}}$ are the $i$ th measured and calculated values, respectively (h), $S_{\mathrm{m} \text {,avg }}$ is the average of the measured values (h), and $n$ is the number of observations.

In case of solar radiation estimation,

$$
\begin{aligned}
& R^{2}=1-\frac{\sum_{i=1}^{n}\left(H_{i, \mathrm{~m}}-H_{i, \mathrm{c}}\right)^{2}}{\sum_{i=1}^{n}\left(H_{i, \mathrm{~m}}-H_{\mathrm{m}, \mathrm{avg}}\right)^{2}} \\
& \mathrm{MPE}=\frac{1}{n} \sum_{i=1}^{n}\left(\frac{H_{i, \mathrm{c}}-H_{i, \mathrm{~m}}}{H_{i, \mathrm{~m}}} \times 100\right)
\end{aligned}
$$




$$
\begin{aligned}
\mathrm{MBE} & =\frac{1}{n} \sum_{i=1}^{n}\left(H_{i, \mathrm{~m}}-H_{i, \mathrm{c}}\right) \\
\mathrm{RMSE} & =\sqrt{\frac{1}{n} \sum_{i=1}^{n}\left(H_{i, \mathrm{~m}}-H_{i, \mathrm{c}}\right)^{2}} \\
\mathrm{MARE} & =\frac{1}{n} \sum_{i=1}^{n}\left|\frac{H_{i, \mathrm{~m}}-H_{i, \mathrm{c}}}{H_{i, \mathrm{~m}}}\right| \\
t \text {-stat } & =\sqrt{\frac{(n-1) \mathrm{MBE}^{2}}{\mathrm{RMSE}^{2}-\mathrm{MBE}^{2}}}
\end{aligned}
$$

where $H_{i, \mathrm{~m}}$ and $H_{i, \mathrm{c}}$ are the $i$ th measured and calculated values, respectively $\left(\mathrm{kWh} / \mathrm{m}^{2}\right), H_{\mathrm{m} \text {,avg }}$ is the average of the calculated and measured values $\left(\mathrm{kWh} / \mathrm{m}^{2}\right.$, and $n$ is the number of observations.

For better data modeling, MPE, MBE, MARE, $t$-stat, and RMSE should be closer to zero, but $R^{2}$ should approach 1.0 as closely as possible.

\section{Results and discussion}

The relationship between $C$ and $\left(1-S / S_{0}\right)$ was found by plotting monthly mean values of $\left(1-S / S_{0}\right)$ with corresponding monthly mean values of $C$ for 20 stations among which 10 are below the tropic of cancer and 10 are above. At first, correlations were found separately for every stations. Then, all the values taken from Zone 1 (below $23.5^{\circ} \mathrm{N}$ ) and from Zone 2 (above $23.5^{\circ} \mathrm{N}$ ) were plotted to find the correlations of these two zones. Finally, all the values from all 20 stations were plotted to get an overall correlation for whole Bangladesh.

Figures 2, 3, 4, 5, and 6 show the plots achieved and their associated models with coefficient of determination $\left(R^{2}\right)$ for different regions and whole Bangladesh.

From Figs. 2 and 3, it is evident that most of the points lie above the straight line $\left(1-S / S_{0}\right)=C$ for cloud fraction 0 to 0.2 , approximately close to the line for cloud fraction 0.3 to 0.5 , and below the line for cloud fraction above 0.5. If Eq. (3) is valid, then all points should line clustered along the $\left(1-S / S_{0}\right)=C$ straight line. However, as it is shown in Figs. 2, 3, 4, 5, and 6, the relationship is not linear and does not coincide with $\left(1-S / S_{0}\right)=C$ line. Rather, it follows a quadratic relationship like:

$$
\left(1-\frac{S}{S_{0}}\right)=a C^{2}+b C+c
$$

This is because of having a systematic error in groundbased cloud cover estimation. We can see that groundbased observers have overestimated overcast conditions
( $C=0.4-0.7)$ and underestimated clear days $(C=0-0.4)$. The main reason why ground-based observers overestimate overcast cloud cover seems to be that clouds with vertical extents appear to fill a greater fraction of the sky when located near the horizon than when they are overhead (Rangarajan et al. 1984). On the other hand, cloud amounts ranging from 0 to 0.4 are underestimated as in winter days (when most of the clear days are observed with low cloud amount) there are mist or fog on the ground level although the sky is clear without any cloud. The Campbell-Stokes sunshine recorder will not burn the card in this condition, but the cloud cover observer will mark it as zero cloud condition. This phenomena is usual in the northwestern part of Bangladesh.

Table 4 shows that the quadratic model gives approximately maximum goodness of fit. Then increasing the order of the equation further does not increase the $R^{2}$ value significantly. Therefore, in this study the higherdegree models were not considered for sunshine duration estimation.

Tables 5 and 6 show the values of regression coefficients of quadratic model for sunshine duration estimation from cloud fraction and their corresponding statistical evaluation. For all the models either regional, zonal, or countrywide, the value of RMSE did not exceed 0.8 and most of the time remained below 0.5 . The MARE values also showed promising results with less than 0.1 for most of the cases. The MPE also remained less than $10 \%$, and MBE also remained less than 0.5 .

Now, comparing all the results we can see that regional models give best fit with the value of $R^{2}$ ranging from 0.9 to 0.99 , whereas models for Zone 1 and Zone 2 also performed well with little less accuracy and fit. The overall model for whole Bangladesh also performed quite well and sometimes better than the zonal models.

As using different models for different regions is quite difficult and the accuracy is not that much deviated, we suggest the following equations for estimation of sunshine duration from cloud amount in Bangladesh:

For Zone $1\left(\leq 23.5^{\circ} \mathrm{N}\right)$ :

$$
\left(1-\frac{S}{S_{0}}\right)=0.4284 C^{2}+0.2462 C+0.2144
$$

For Zone $2\left(\geq 23.5^{\circ} \mathrm{N}\right)$ :

$$
\left(1-\frac{S}{S_{0}}\right)=0.5102 C^{2}+0.0911 C+0.2703
$$

For whole Bangladesh:

$$
\left(1-\frac{S}{S_{0}}\right)=0.4548 C^{2}+0.1851 C+0.2385
$$

Now using calculated monthly mean values of $S$ from the corresponding mean of $C$, we can compute monthly 
Sarkar Renewables (2016)3:11

Page 8 of 15
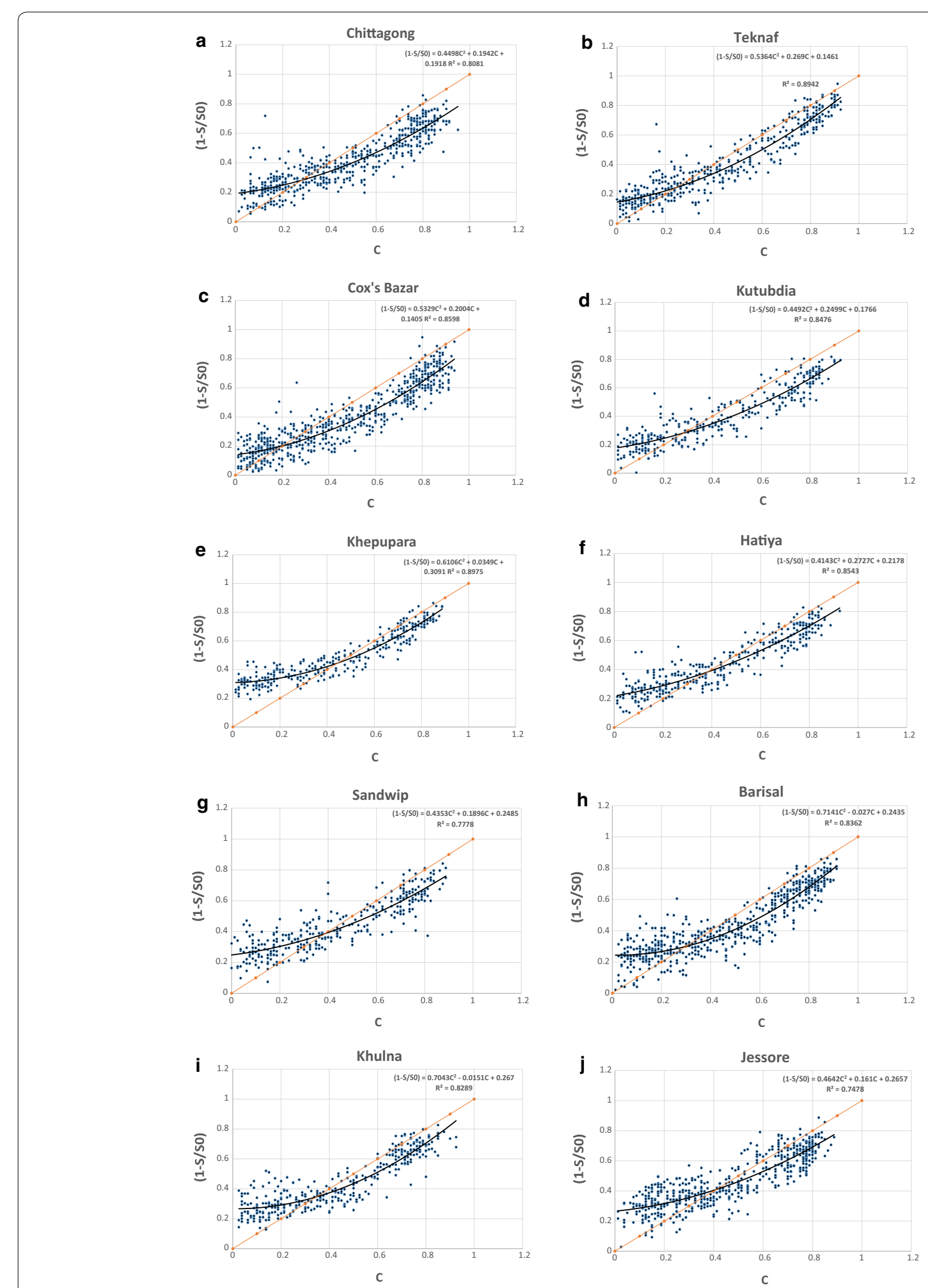

Fig. 2 Correlation between $C$ and $\left(1-S / S_{0}\right)$ for different regions of Zone 1 
Sarkar Renewables (2016)3:11

Page 9 of 15
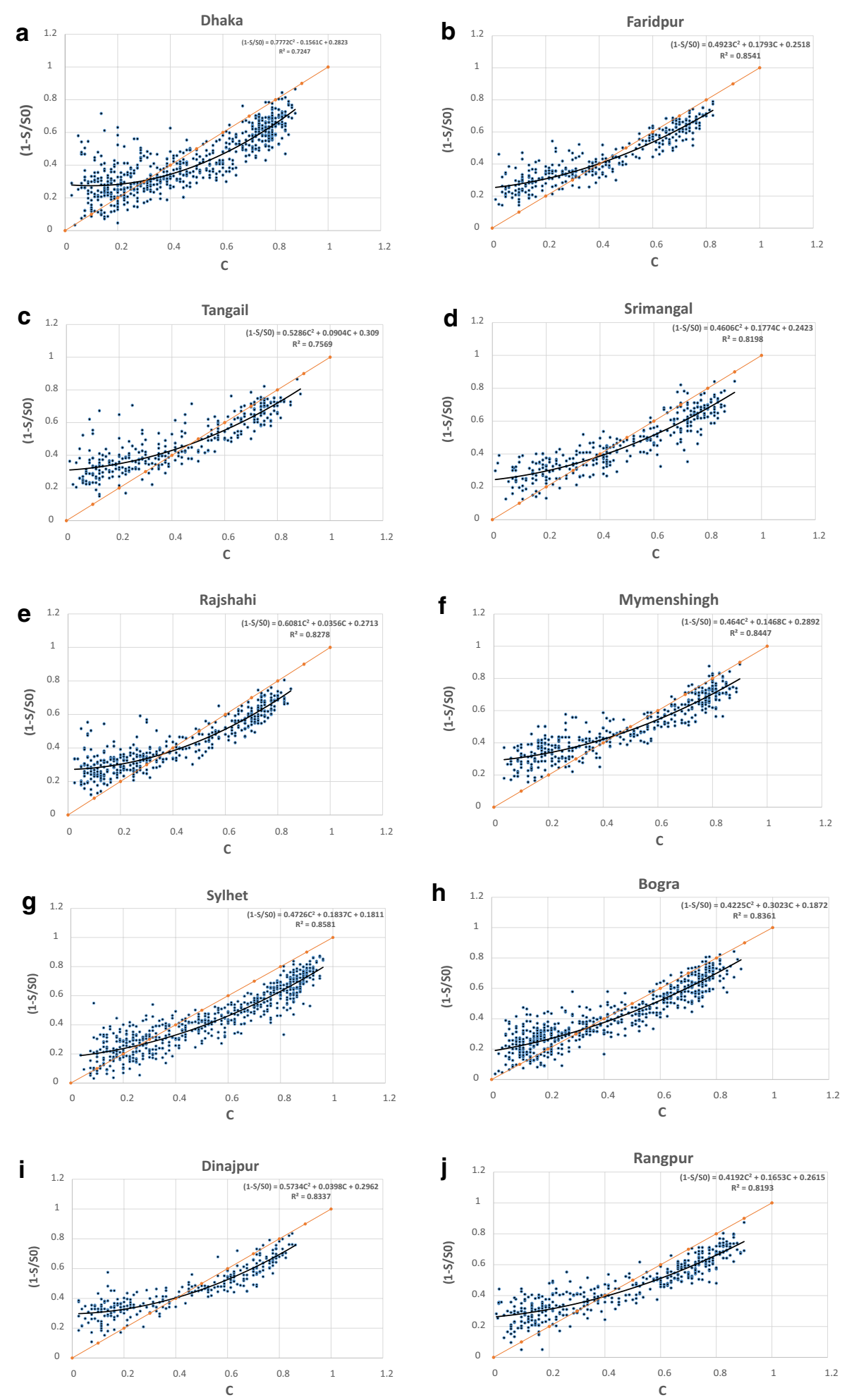

Fig. 3 Correlation between $C$ and $\left(1-S / S_{0}\right)$ for different regions of Zone 2 


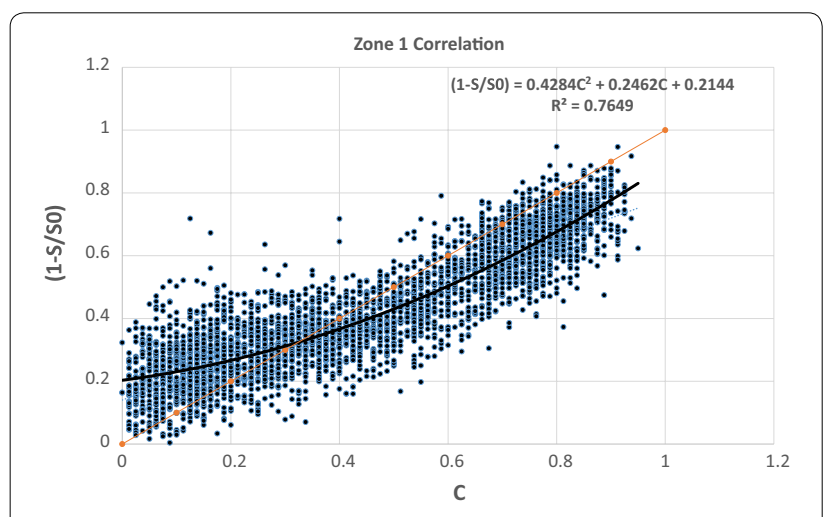

Fig. 4 Correlation between $C$ and $\left(1-S / S_{0}\right)$ for Zone 1

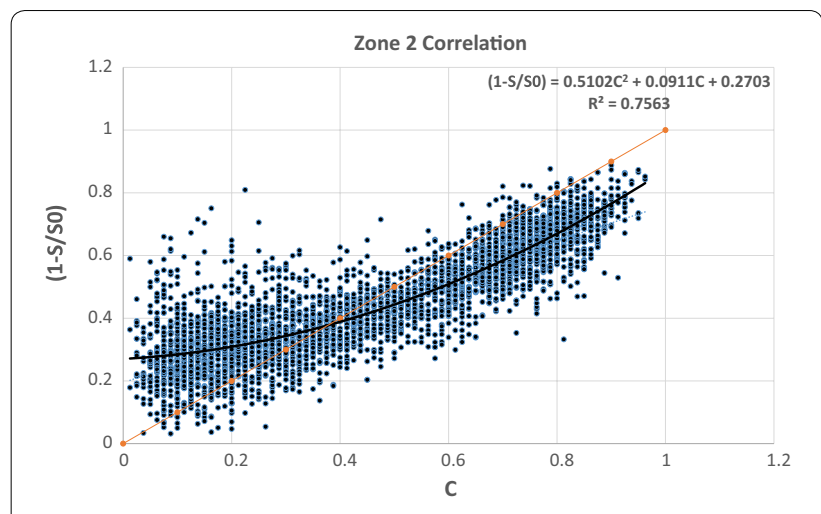

Fig. 5 Correlation between $C$ and $\left(1-S / S_{0}\right)$ for Zone 2

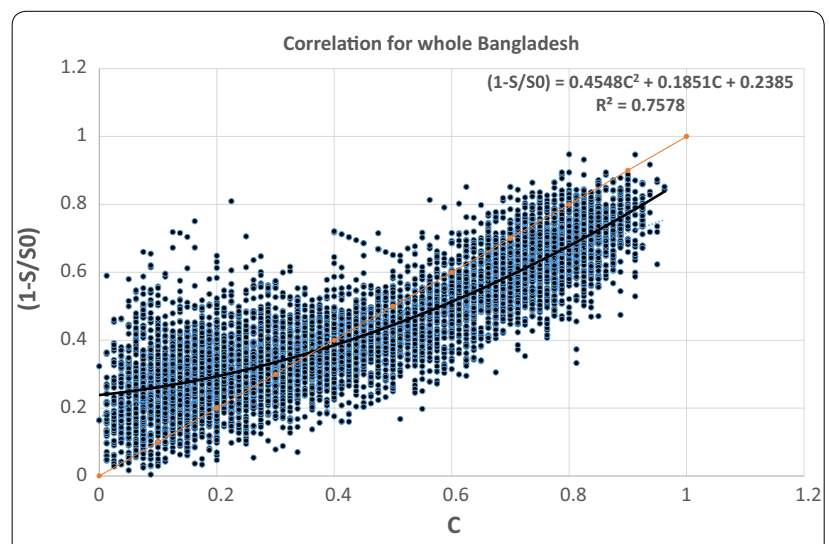

Fig. 6 Correlation between $C$ and $\left(1-S / S_{0}\right)$ for whole Bangladesh

mean values of global solar radiation $H$ using standard techniques developed by other researchers (Sen 2007; AlMostafa et al. 2014).

Table 7 shows different models to estimate solar radiation directly from cloud cover data. After the statistical error test, it is seen that the higher-degree models perform better with lowest RMSE values. The fifth-degree model performs best, but to avoid complexity one can easily use quadratic or third-degree model to estimate solar radiation. Considering both, the simplicity of the model and accuracy, we can recommend the thirddegree or cubic model for use:

$$
H / H_{0}=1.9104 C^{3}-3.1785 C^{2}+1.3352 C+0.3669
$$

Finally, Table 3 shows that we have measured global solar radiation field data only for five stations of BMD, and those were only for 1 year for all the four stations except Dhaka. Therefore, we have chosen Dhaka station's data to compare all the methods of estimation. Figure 7 shows the comparison of different estimated and measured global solar radiation $(H)$ of Dhaka, Bangladesh, and it is evident that all the models performed quite well and give approximately close estimation of solar radiation for Dhaka.

Figure 8 shows the comparative errors in global solar radiation estimation of different methods. We can see from the figure that estimating solar radiation from sunshine duration gives the best estimation with quite low RMSE value of $0.13\left(\mathrm{kWh} / \mathrm{m}^{2}\right)$. However, if there is no sunshine duration data available for a site, then it is better to estimate solar radiation from direct cloud cover estimation models. Estimating sunshine duration first from cloud data to estimate solar radiation introduces more error as it has to go through the modeling stage twice. In case of requirement of sunshine duration data, the estimation from cloud cover data is quite helpful and gives quite close estimation.

\section{Conclusions}

As a developing country with very less investment in technology to measure solar radiation directly, Bangladesh needs models to estimate solar radiation from other climatological data like cloud cover. Therefore, both the models to estimate sunshine hours from cloud cover of various regions of Bangladesh are established along with models to estimate solar radiation directly from cloud cover data. As sunshine hour has a latitudinal dependence, two general models for Zone $1 \leq 23.5^{\circ}$ and Zone $2 \geq 23.5^{\circ}$ are developed to estimate sunshine hours with better accuracy. Finally, a quadratic relationship for whole Bangladesh is proposed. In case of models to estimate solar radiation directly from cloud cover data, few linear and higher-order models are proposed. All the developed models are checked statistically. The value of RMSE did not exceed 0.8 , and most of the time remained below 0.5. The MARE values also showed promising results with less than 0.1 for most of the cases. The MPE also remained less than $10 \%$, and MBE also remained 
Table 4 Different models to estimate sunshine duration from cloud fraction of Bangladesh and their equations with coefficient of determination

\begin{tabular}{lll}
\hline Model type & Model equations & Goodness of fit $\left(\boldsymbol{R}^{\mathbf{2}}\right)$ \\
\hline Linear & $\left(1-S / S_{0}\right)=0.6034 C+0.1739$ & 0.7402 \\
Qudratic & $\left(1-S / S_{0}\right)=0.4548 C^{2}+0.1851 C+0.2385$ \\
Third degree & $\left(1-S / S_{0}\right)=-0.0855 C^{3}+0.5721 C^{2}+0.1409 C+0.2424$ \\
Fourth degree & $\left(1-S / S_{0}\right)=-2.6566 C^{4}+4.8588 C^{3}-2.4378 C^{2}+0.7996 C+0.2039$ \\
Fifth degree & $\left(1-S / S_{0}\right)=0.273 C^{5}-3.2931 C^{4}+5.3912 C^{3}-2.6292 C^{2}+0.8272 C+0.2028$ \\
\hline
\end{tabular}

Table 5 Correlation coefficients of quadratic model for sunshine duration estimation from cloud fraction and statistical error tests of different stations of Zone 1

\begin{tabular}{|c|c|c|c|c|c|c|c|c|c|c|}
\hline Stations & Model & $a$ & $b$ & $c$ & $R^{2}$ & MPE & MBE & MARE & RMSE & $t$-stat \\
\hline \multirow[t]{3}{*}{ Teknaf } & Regional & 0.5364 & 0.269 & 0.1461 & 0.9848 & 1.7305 & -0.0541 & 0.0498 & 0.2808 & 0.6511 \\
\hline & Zone 1 & 0.4284 & 0.2462 & 0.2144 & 0.9309 & -0.8473 & 0.2748 & 0.0902 & 0.5985 & 1.714 \\
\hline & Countrywide & 0.4548 & 0.1851 & 0.2385 & 0.9038 & -0.8258 & 0.3196 & 0.1057 & 0.7064 & 1.6829 \\
\hline \multirow[t]{3}{*}{ Cox's Bazar } & Regional & 0.5329 & 0.2004 & 0.1405 & 0.9699 & 1.7093 & -0.066 & 0.0506 & 0.3511 & 0.6356 \\
\hline & Zone 1 & 0.4284 & 0.2462 & 0.2144 & 0.8405 & -9.3925 & 0.707 & 0.1024 & 0.8083 & 5.9863 \\
\hline & Countrywide & 0.4548 & 0.1851 & 0.2385 & 0.8157 & -9.4079 & 0.7441 & 0.1083 & 0.8688 & 5.5043 \\
\hline \multirow[t]{3}{*}{ Kutubdia } & Regional & 0.4492 & 0.2499 & 0.1766 & 0.9644 & 1.4224 & -0.0627 & 0.0413 & 0.3178 & 0.6684 \\
\hline & Zone 1 & 0.4284 & 0.2462 & 0.2144 & 0.9325 & -3.9831 & 0.3033 & 0.0557 & 0.4376 & 3.1897 \\
\hline & Countrywide & 0.4548 & 0.1851 & 0.2385 & 0.9141 & -4.1987 & 0.3461 & 0.0656 & 0.4939 & 3.2588 \\
\hline \multirow[t]{3}{*}{ Khepupara } & Regional & 0.6106 & 0.0349 & 0.3091 & 0.9505 & -0.6233 & 0.0511 & 0.0467 & 0.3421 & 0.5018 \\
\hline & Zone 1 & 0.4284 & 0.2462 & 0.2144 & 0.8192 & 9.3429 & -0.5197 & 0.1019 & 0.654 & 4.341 \\
\hline & Countrywide & 0.4548 & 0.1851 & 0.2385 & 0.8447 & 9.2113 & -0.4843 & 0.101 & 0.6061 & 4.4085 \\
\hline \multirow[t]{3}{*}{ Hatiya } & Regional & 0.4143 & 0.2727 & 0.2178 & 0.9498 & 2.7677 & -0.1187 & 0.0486 & 0.3709 & 1.1207 \\
\hline & Zone 1 & 0.4284 & 0.2462 & 0.2144 & 0.9255 & 5.342 & -0.2591 & 0.0653 & 0.4519 & 2.3214 \\
\hline & Countrywide & 0.4548 & 0.1851 & 0.2385 & 0.9168 & 5.1502 & -0.219 & 0.0698 & 0.4777 & 1.7109 \\
\hline \multirow[t]{3}{*}{ Chittagong } & Regional & 0.4498 & 0.1942 & 0.1918 & 0.9434 & 2.2874 & -0.0931 & 0.0506 & 0.3805 & 0.8374 \\
\hline & Zone 1 & 0.4284 & 0.2462 & 0.2144 & 0.8871 & -5.8735 & 0.4022 & 0.0716 & 0.5374 & 3.7416 \\
\hline & Countrywide & 0.4548 & 0.1851 & 0.2385 & 0.8778 & -5.9425 & 0.4325 & 0.0761 & 0.5591 & 4.0474 \\
\hline \multirow[t]{3}{*}{ Sandwip } & Regional & 0.4353 & 0.1896 & 0.2485 & 0.899 & 4.823 & -0.2205 & 0.0625 & 0.4491 & 1.8692 \\
\hline & Zone 1 & 0.4284 & 0.2462 & 0.2144 & 0.8844 & 6.5565 & -0.3583 & 0.0705 & 0.4803 & 3.7146 \\
\hline & Countrywide & 0.4548 & 0.1851 & 0.2385 & 0.8834 & 6.1214 & -0.3089 & 0.0693 & 0.4824 & 2.7645 \\
\hline \multirow[t]{3}{*}{ Rangamati } & Regional & 0.7043 & -0.0151 & 0.267 & 0.9123 & 3.9047 & -0.1673 & 0.0619 & 0.4377 & 1.3727 \\
\hline & Zone 1 & 0.4284 & 0.2462 & 0.2144 & 0.8972 & 4.5865 & -0.1984 & 0.0656 & 0.4738 & 1.5293 \\
\hline & Countrywide & 0.4548 & 0.1851 & 0.2385 & 0.883 & 4.5021 & -0.1718 & 0.0716 & 0.5056 & 1.1982 \\
\hline \multirow[t]{3}{*}{ Barisal } & Regional & 0.7141 & -0.027 & 0.2435 & 0.9698 & 2.3692 & -0.0989 & 0.044 & 0.2998 & 1.1589 \\
\hline & Zone 1 & 0.4284 & 0.2462 & 0.2144 & 0.9454 & -0.8815 & 0.1138 & 0.0506 & 0.4031 & 0.9764 \\
\hline & Countrywide & 0.4548 & 0.1851 & 0.2385 & 0.9391 & -0.8889 & 0.1434 & 0.0543 & 0.4258 & 1.1867 \\
\hline \multirow[t]{3}{*}{ Maijdee Court } & Regional & 0.7043 & -0.0151 & 0.2670 & 0.8936 & 6.4040 & -0.3615 & 0.0783 & 0.4995 & 3.4782 \\
\hline & Zone 1 & 0.4284 & 0.2462 & 0.2144 & 0.8415 & 8.4215 & -0.4696 & 0.0925 & 0.6098 & 4.0045 \\
\hline & Countrywide & 0.4548 & 0.1851 & 0.2385 & 0.8626 & 8.1031 & -0.4228 & 0.0871 & 0.5678 & 3.6997 \\
\hline \multirow[t]{3}{*}{ Jessore } & Regional & 0.4642 & 0.1610 & 0.2657 & 0.9292 & 2.6934 & -0.1368 & 0.0480 & 0.3677 & 1.3294 \\
\hline & Zone 1 & 0.4284 & 0.2462 & 0.2144 & 0.8339 & 6.6521 & -0.4023 & 0.0730 & 0.5633 & 3.3839 \\
\hline & Countrywide & 0.4548 & 0.1851 & 0.2385 & 0.8684 & 6.3433 & -0.3619 & 0.0709 & 0.5014 & 3.4590 \\
\hline \multirow[t]{3}{*}{ Khulna } & Regional & 0.7043 & -0.0151 & 0.2670 & 0.9109 & 5.9973 & -0.2692 & 0.0712 & 0.4829 & 2.2271 \\
\hline & Zone 1 & 0.4284 & 0.2462 & 0.2144 & 0.8764 & 7.1841 & -0.3415 & 0.0859 & 0.5687 & 2.4906 \\
\hline & Countrywide & 0.4548 & 0.1851 & 0.2385 & 0.8722 & 6.7666 & -0.2903 & 0.0857 & 0.5783 & 1.9253 \\
\hline
\end{tabular}


Table 6 Correlation coefficients of quadratic model for sunshine duration estimation from cloud fraction and statistical error tests of different stations of Zone 2

\begin{tabular}{|c|c|c|c|c|c|c|c|c|c|c|}
\hline Stations & Model & $a$ & $b$ & $c$ & $R^{2}$ & MPE & MBE & MARE & RMSE & $\overline{t \text {-stat }}$ \\
\hline \multirow[t]{3}{*}{ Faridpur } & Regional & 0.4923 & 0.1793 & 0.2518 & 0.9355 & -1.5308 & 0.0807 & 0.0412 & 0.3255 & 0.8489 \\
\hline & Zone 2 & 0.5102 & 0.0911 & 0.2703 & 0.9514 & 2.1836 & -0.1116 & 0.0375 & 0.2826 & 1.4264 \\
\hline & Countrywide & 0.4548 & 0.1851 & 0.2385 & 0.9359 & 2.6308 & -0.1623 & 0.0384 & 0.3247 & 1.9139 \\
\hline \multirow[t]{3}{*}{ Dhaka } & Regional & 0.7772 & -0.1561 & 0.2823 & 0.9585 & 0.1666 & 0.0000 & 0.0368 & 0.2820 & 0.0000 \\
\hline & Zone 2 & 0.5102 & 0.0911 & 0.2703 & 0.8751 & -5.0073 & 0.3470 & 0.0612 & 0.4894 & 3.3349 \\
\hline & Countrywide & 0.4548 & 0.1851 & 0.2385 & 0.8672 & -4.8924 & 0.3180 & 0.0637 & 0.5046 & 2.6918 \\
\hline \multirow[t]{3}{*}{ Ishurdi } & Regional & 0.6081 & 0.0356 & 0.2713 & 0.9126 & 0.3645 & -0.0338 & 0.0401 & 0.3831 & 0.2940 \\
\hline & Zone 2 & 0.5102 & 0.0911 & 0.2703 & 0.9190 & 1.0880 & -0.0549 & 0.0433 & 0.3688 & 0.4994 \\
\hline & Countrywide & 0.4548 & 0.1851 & 0.2385 & 0.8837 & 1.5396 & -0.1044 & 0.0476 & 0.4420 & 0.8062 \\
\hline \multirow[t]{3}{*}{ Tangail } & Regional & 0.5286 & 0.0904 & 0.3090 & 0.9152 & 1.4147 & -0.0402 & 0.0538 & 0.3871 & 0.3470 \\
\hline & Zone 2 & 0.5102 & 0.0911 & 0.2703 & 0.7352 & 10.5005 & -0.5564 & 0.1053 & 0.6845 & 4.6278 \\
\hline & Countrywide & 0.4548 & 0.1851 & 0.2385 & 0.7047 & 10.9350 & -0.6054 & 0.1093 & 0.7227 & 5.0868 \\
\hline \multirow[t]{3}{*}{ Srimangal } & Regional & 0.6081 & 0.0356 & 0.2713 & 0.7843 & 8.3236 & -0.4115 & 0.0931 & 0.6273 & 2.8828 \\
\hline & Zone 2 & 0.5102 & 0.0911 & 0.2703 & 0.7496 & 8.6157 & -0.4109 & 0.1012 & 0.6759 & 2.5393 \\
\hline & Countrywide & 0.4548 & 0.1851 & 0.2385 & 0.7721 & 9.0217 & -0.4599 & 0.0965 & 0.6447 & 3.3764 \\
\hline \multirow[t]{3}{*}{ Rajshahi } & Regional & 0.6081 & 0.0356 & 0.2713 & 0.9384 & 1.0918 & -0.0559 & 0.0408 & 0.3268 & 0.5761 \\
\hline & Zone 2 & 0.5102 & 0.0911 & 0.2703 & 0.9293 & 1.5105 & -0.0615 & 0.0435 & 0.3501 & 0.5920 \\
\hline & Countrywide & 0.4548 & 0.1851 & 0.2385 & 0.9233 & 2.1406 & -0.1253 & 0.0420 & 0.3646 & 1.2136 \\
\hline \multirow[t]{3}{*}{ Mymenshingh } & Regional & 0.4640 & 0.1468 & 0.2892 & 0.8973 & -1.5783 & 0.0525 & 0.0577 & 0.3751 & 0.4693 \\
\hline & Zone 2 & 0.5102 & 0.0911 & 0.2703 & 0.8450 & 5.1715 & -0.3305 & 0.0530 & 0.4608 & 3.4153 \\
\hline & Countrywide & 0.4548 & 0.1851 & 0.2385 & 0.7744 & 5.4347 & -0.3680 & 0.0577 & 0.5559 & 2.9286 \\
\hline \multirow[t]{3}{*}{ Sylhet } & Regional & 0.4726 & 0.1837 & 0.1811 & 0.9696 & 1.4943 & -0.0670 & 0.0428 & 0.2979 & 0.7662 \\
\hline & Zone 2 & 0.5102 & 0.0911 & 0.2703 & 0.8629 & -8.6237 & 0.5557 & 0.0929 & 0.6327 & 6.0960 \\
\hline & Countrywide & 0.4548 & 0.1851 & 0.2385 & 0.8685 & -9.0145 & 0.5502 & 0.0918 & 0.6195 & 6.4128 \\
\hline \multirow[t]{3}{*}{ Bogra } & Regional & 0.4225 & 0.3023 & 0.1872 & 0.9447 & 0.7061 & -0.0651 & 0.0400 & 0.3342 & 0.6587 \\
\hline & Zone 2 & 0.5102 & 0.0911 & 0.2703 & 0.9368 & -0.5272 & 0.0957 & 0.0428 & 0.3573 & 0.9225 \\
\hline & Countrywide & 0.4548 & 0.1851 & 0.2385 & 0.9569 & -0.0382 & 0.0379 & 0.0384 & 0.2950 & 0.4306 \\
\hline \multirow[t]{3}{*}{ Dinajpur } & Regional & 0.5734 & 0.0398 & 0.2962 & 0.8849 & 3.6956 & -0.2112 & 0.0578 & 0.4080 & 2.0072 \\
\hline & Zone 2 & 0.5102 & 0.0911 & 0.2703 & 0.7796 & 7.4499 & -0.4435 & 0.0778 & 0.5646 & 4.2089 \\
\hline & Countrywide & 0.4548 & 0.1851 & 0.2385 & 0.7421 & 8.3670 & -0.5273 & 0.0836 & 0.6109 & 5.6691 \\
\hline \multirow[t]{3}{*}{ Syedpur } & Regional & 0.6081 & 0.0356 & 0.2713 & 0.9194 & 2.5952 & -0.1678 & 0.0448 & 0.3230 & 2.0160 \\
\hline & Zone 2 & 0.5102 & 0.0911 & 0.2703 & 0.9168 & 3.0251 & -0.1768 & 0.0462 & 0.3282 & 2.1209 \\
\hline & Countrywide & 0.4548 & 0.1851 & 0.2385 & 0.8961 & 3.5404 & -0.2300 & 0.0509 & 0.3666 & 2.6720 \\
\hline \multirow[t]{3}{*}{ Rangpur } & Regional & 0.4192 & 0.1653 & 0.2615 & 0.7947 & 6.5107 & -0.3662 & 0.0771 & 0.5369 & 3.0928 \\
\hline & Zone 2 & 0.5102 & 0.0911 & 0.2703 & 0.7938 & 6.6344 & -0.3794 & 0.0764 & 0.5380 & 3.2992 \\
\hline & Countrywide & 0.4548 & 0.1851 & 0.2385 & 0.7547 & 7.2168 & -0.4364 & 0.0772 & 0.5868 & 3.6901 \\
\hline
\end{tabular}

Table 7 Regression models to estimate solar radiation directly from cloud cover fraction

\begin{tabular}{|c|c|c|c|c|c|c|c|c|}
\hline \# & Model type & Equations & $R^{2}$ & MBE & MPE & MARE & RMSE & t-stat \\
\hline 1 & Linear & $H / H_{0}=-0.2302 C+0.5713$ & 0.9936 & 0.0213 & 0.6566 & 0.0716 & 0.3315 & 0.2139 \\
\hline 2 & Quadratic & $H / H_{0}=-0.4585 C^{2}+0.2087 C+0.4942$ & 0.9953 & 0.0157 & 0.4905 & 0.0585 & 0.2834 & 0.1850 \\
\hline 3 & Third degree & $H / H_{0}=1.9104 C^{3}-3.1785 C^{2}+1.3352 C+0.3669$ & 0.9954 & 0.0135 & 0.4482 & 0.0481 & 0.2831 & 0.1593 \\
\hline 4 & Fourth degree & $H / H_{0}=-11.449 C^{4}+23.22 C^{3}-16.729 C^{2}+4.7227 C+0.0963$ & 0.9957 & 0.0008 & 0.8008 & 0.0543 & 0.2721 & 0.0098 \\
\hline 5 & Fifth degree & $H / H_{0}=120.19 C^{5}-299.15 C^{4}+281.59 C^{3}-124.07 C^{2}+25.073 C-1.3032$ & 0.9974 & 0.0151 & 0.1131 & 0.0344 & 0.2107 & 0.2395 \\
\hline 6 & Logarithmic & $H / H_{0}=-0.083 \ln (C)+0.386$ & 0.9905 & 0.0164 & 0.8877 & 0.0909 & 0.4052 & 0.1347 \\
\hline 7 & Exponential & $H / H 0=0.5819 \exp (-0.509 C)$ & 0.9931 & 0.0362 & 0.3475 & 0.0728 & 0.3445 & 0.3505 \\
\hline 8 & Power & $H / H O=0.3862 C^{(-0.184)}$ & 0.9899 & 0.0376 & 0.4436 & 0.0916 & 0.4184 & 0.2994 \\
\hline
\end{tabular}




\section{Comparison of different estimated and measured global solar radiation (H) of Dhaka, Bangladesh}

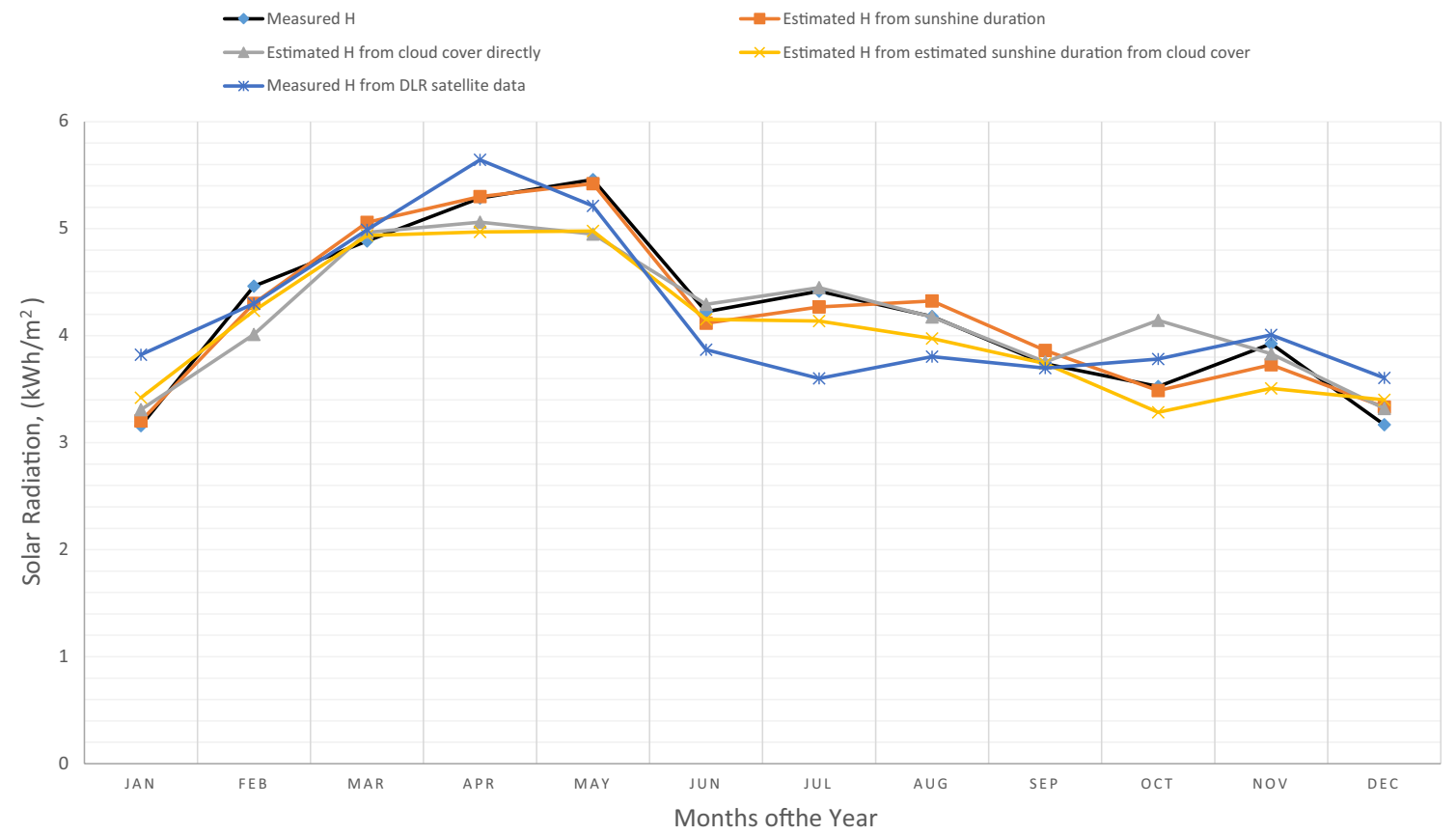

Fig. 7 Comparison of different estimated and measured global solar radiation ( $H$ ) of Dhaka, Bangladesh

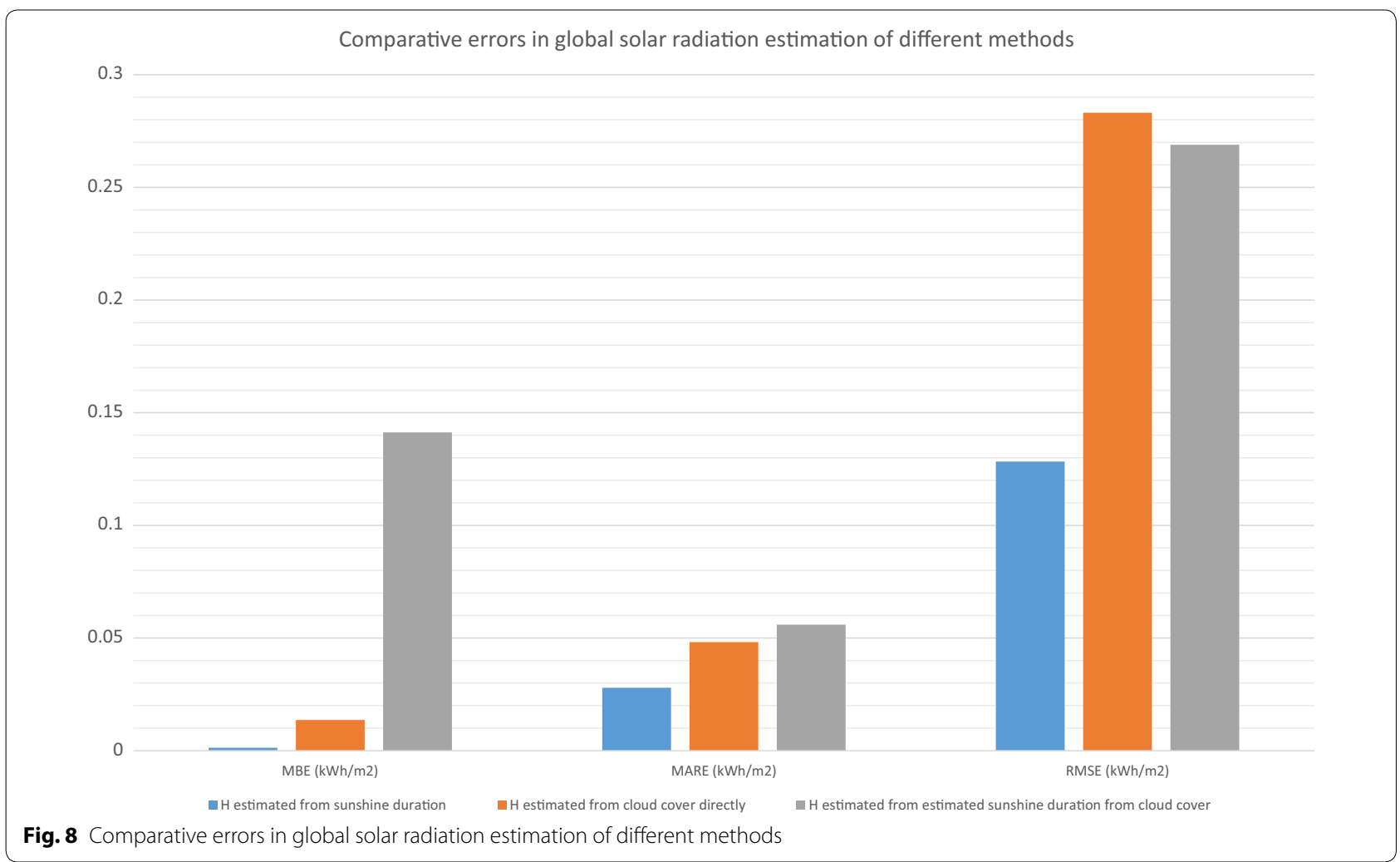


less than 0.5. The regional models give best fit with the value of $R^{2}$ ranging from 0.9 to 0.99 , Whereas sunshine duration measurement models for Zone 1 and Zone 2 also performed well with little less accuracy and fit.

As using different models for different regions is quite difficult and the accuracy is not that much deviated, we suggest the model developed for whole Bangladesh in Eq. (24) to be used for estimation of sunshine duration from cloud amount in Bangladesh. On the other hand, Eq. (25) can be used to estimate solar radiation directly from cloud fraction in Bangladesh. It is also seen from the study that for a small country like Bangladesh separating data according to latitude has no significant effect.

Finally, it is always better to estimate solar radiation from sunshine duration as it gives the best estimation with quite less error. However, if there is no sunshine duration data available for a site, then solar radiation can be estimated directly from cloud cover data. Estimating sunshine duration first from cloud data to estimate solar radiation introduces more error as it has to go through the modeling stage twice. In case of requirement of sunshine duration data, the estimation from cloud cover is quite helpful.

\section{List of symbols}

$H \quad$ global solar radiation on the horizontal surface $\left(\mathrm{kWh} / \mathrm{m}^{2}\right)$

$H_{0} \quad$ extraterrestrial solar radiation $\left(\mathrm{kWh} / \mathrm{m}^{2}\right)$

C cloud fraction

$S \quad$ sunshine duration (h)

$S_{0} \quad$ maximum possible hours of sunshine of a day (h)

$D \quad$ day number of the year counting from first January

ob latitude $\left(^{\circ}\right)$

$\omega_{\mathrm{s}} \quad$ sunset hour angle $\left({ }^{\circ}\right)$

$\delta \quad$ solar declination $\left(^{\circ}\right)$

$R^{2} \quad$ coefficient of determination

MPE mean percentage error

MBE mean bias error

RMSE root mean square error

MARE mean absolute relative error

$t$-stat $t$-statistic

\begin{tabular}{ll}
\multicolumn{2}{l}{ Subscripts } \\
$i$ & $i$ th value \\
$\mathrm{m}$ & measured \\
$\mathrm{c}$ & calculated \\
avg & average
\end{tabular}

\section{Acknowledgements}

The author would like to thank Institute of Energy, University of Dhaka, Bangladesh Meteorological Department, and Bangladesh Agricultural Research

Council for their data and support.

\section{Competing interests}

The author declare that he has no competing interests.

Received: 23 November 2015 Accepted: 24 February 2016

Published online: 15 March 2016

\section{References}

Ahiduzzaman, M., \& Islam, A. S. (2011). Greenhouse gas emission and renewable energy sources for sustainable development in Bangladesh. Renewable and Sustainable Energy Reviews, 15, 4659-4666.

Akinoglu, B., \& Ecevit, A. (1990). Construction of a quadratic model using modified angstrom coefficients to estimate global solar radiation. Solar Energy, 45, 85-92.

Almorox, J., \& Hontoria, C. (2004). Global solar radiation estimation using sunshine duration in Spain. Energy Conversion and Management, 45, 1529-1535.

Al-Mostafa, Z. A., Maghrabi, A. H., \& Al-Shehri, S. M. (2014). Sunshine-based global radiation models: A review and case study. Energy Conversion and Management, 84, 209-216. doi:10.1016/j.enconman.2014.04.021.

Al-Mostafa, Z. A., Maghrabi, A. H., \& Al-Shehri, S. M. (2014). Sunshine-based global radiation models: A review and case study. Energy Conversion and Management, 84, 209-216.

Ampratwum, D., \& Dorvlo, A. (1990). Estimation of solar radiation from the number of sunshine hours. Applied Energy, 62, 161-167.

Ampratwum, D., \& Dorvlo, A. (1990). Estimation of solar radiation from the number of sunshine hours. Applied Energy, 62, 161-167.

Angstrom, A. (1924). Solar and terrestrial radiation. Quarterly Journal of the Royal Meteorological Society, 50, 121-125.

Babatunde, E. B., \& Aro, T. O. (1995). Relationship between "clearness index" and "cloudiness index" at a tropical station (Ilorin, Nigeria). Renewable Energy, 6(7), 801-805. doi:10.1016/0960-1481(94)00087-M.

Badescu, V., \& Dumitrescu, A. (2014). New types of simple non-linear models to compute solar global irradiance from cloud cover amount. Journal of Atmospheric and Solar-Terrestrial Physics, 117, 54-70. doi:10.1016/j. jastp.2014.05.010.

Bakirci, K. (2015). Models for the estimation of diffuse solar radiation for typical cities in turkey. Energy, 82, 827-838. doi:10.1016/j.energy.2015.01.093.

Bangladesh Power Development Board. (2015). http://www.bpdb.gov.bd/ keystatistics.htm

Black, J. (1956). The distribution of solar radiation over the earth's surface. Archiv für Meteorologie, Geophysik und Bioklimatologie, 7, 165-189.

BMD: Bangladesh Meteorological Department. (2015). http://www.bmd.gov.bd/

Chelbi, M., Gagnon, Y., \& Waewsak, J. (2015). Solar radiation mapping using sunshine duration-based models and interpolation techniques: Application to tunisia. Energy Conversion and Management, 101, 203-215.

Despotovic, M., Nedic, V., Despotovic, D., \& Cvetanovic, S. (2015). Review and statistical analysis of different global solar radiation sunshine models. Renewable and Sustainable Energy Reviews, 52, 1869-1880.

Duffie, J. A., \& Beckman, W. A. (2006). Solar engineering of thermal processes (3rd ed.). Hoboken, NJ: Wiley.

Ehnberg, J. S. G., \& Bollen, M. H. J. (2005). Simulation of global solar radiation based on cloud observations. Solar Energy, 78(2), 157-162. In ISES solar world congress 2003. doi:10.1016/j.solener.2004.08.016

Elagib, N., Babiker, S., \& Alvi, S. (1998). New empirical models for global solar radiation over Bahrain. Energy Conversion and Management, 39(8), $827-835$.

Ertekin, C., \& Yaldiz, O. (2000). Comparison of some existing models for estimating global solar radiation for Antalya (Turkey). Energy Conversion and Management, 41, 311-330. 
German Aerospace Center (DLR) Data. (2015). http://www.dlr.de/tt/desktopdefault.aspx/tabid-2885/4422_read-6548/

Hargreaves, G., \& Samani, Z. (1982). Estimating potential evapotranspiration. Journal of the Irrigation and Drainage Division, ASCE, 108(1 IR3), 223-230.

labal, M. (1983). An introduction to solar radiation (4th ed.). Don Mills: Academic Press.

Jong, R., \& Stewart, D. (1993). Estimating global radiation from common meteorological variables in western Canada. Canadian Journal of Plant Science, 73, 509-518.

Katiyar, A. K., \& Pandey, C. K. (2010). Simple correlation for estimating the global solar radiation on horizontal surfaces in india. Energy, 35(12). In The 3rd international conference on sustainable energy and environmental protection, SEEP 2009, pp. 5043-5048. doi:10.1016/j.energy.2010.08.014.

Khadem, S., Ullah, S., Aditya, S., Ghosh, H., \& Mariam, L. (2007). Country report of solar and wind energy resource assessment (SWERA). Bangladesh: Renewable Energy Research Center, University of Dhaka.

Kimball, H. (1919). Variations in the total and luminous solar radiation with geographical position in the United States. Monthly Weather Review, 47(II), 769-793.

Li, H., Maa, W., Lian, Y., Wang, X., \& Zhao, L. (2011). Global solar radiation estimation with sunshine duration in Tibet, China. Renewable Energy, 36, 3141-3145.

Liu, J., Linderholm, H., Chen, D., Zhou, X., Flerchinger, G. N., Yu, Q., et al. (2015). Changes in the relationship between solar radiation and sunshine duration in large cities of China. Energy, 82, 589-600. doi:10.1016/j. energy.2015.01.068.

Mani, A., Chacko, O., Krishnamurthy, V., \& Desikan, V. (1967). Distribution of global and net radiation over the indian ocean and its environments. Archiv für Meteorologie, Geophysik und Bioklimatologie, 82(B15), 1-2.

Manzano, A., MartÃn, M. L., Valero, F., \& Armenta, C. (2015). A single method to estimate the daily global solar radiation from monthly data. Atmospheric Research, 166, 70-82. doi:10.1016/j.atmosres.2015.06.017.
Mondal, M., \& Islam, A. S. (2011). Potential and viability of grid-connected solar PV system in Bangladesh. Renewable Energy, 36, 1869-1874.

Morf, H. (2014). Sunshine and cloud cover prediction based on Markov processes. Solar Energy, 110, 615-626. doi:10.1016/j.solener.2014.09.044.

Nimnuan, P., \& Janjai, S. (2012). An approach for estimating average daily global solar radiation from cloud cover in Thailand. Procedia Engineering, 32, 399-406. doi:10.1016/j.proeng.2012.01.1285. ISEEC.

Prescott, J. (1940). Evaporation from a water surface in relation to solar radiation. Transactions of the Royal Society of South Australia, 64, 114-125.

Rangarajan, S., Swaminathan, M., \& Mani, A. (1984). Computation of solar radiation from observations of cloud cover. Solar Energy, 32(4), 553-556.

Rashid, H. E. (2006). Geography of Bangladesh. Dhaka: University Press.

Reddy, S. J. (1974). An empirical method for estimating sunshine from total cloud amount. Solar Energy, 15(4), 281-285. doi:10.1016/0038-092X(74)90017-6.

Robaa, S. M. (2008). Evaluation of sunshine duration from cloud data in Egypt. Energy, 33(5), 785-795. doi:10.1016/j.energy.2007.12.001.

Schillings, C., Meyer, R., \& Trieb, F. (2004). Final report of solar and wind energy resource assessment (SWERA), UNEP/GEF.

Sen, Z. (2007). Simple nonlinear solar irradiation estimation model. Renewable Energy, 32, 342-350.

Sen, Z. (2007). Simple nonlinear solar irradiation estimation model. Renew Energy, 32, 342-350.

Shahid, S. (2010). Recent trends in the climate of Bangladesh. Climate Research, 42(3), 185-193.

Yang, D., Jirutitijaroen, P., \& Walsh, W. M. (2012). Hourly solar irradiance time series forecasting using cloud cover index. Solar Energy, 86(12), 3531-3543. doi:10.1016/j.solener.2012.07.029. Solar Resources.

\section{Submit your manuscript to a SpringerOpen ${ }^{\circ}$ journal and benefit from:}

- Convenient online submission

- Rigorous peer review

- Immediate publication on acceptance

- Open access: articles freely available online

- High visibility within the field

- Retaining the copyright to your article

Submit your next manuscript at $>$ springeropen.com 